\title{
Prediction of Track of Super Cyclone Amphan using WRF-ARW Model
}

\author{
Sabikun Nahar ${ }^{1}$, Dewan Abdul Quadir ${ }^{1}$, Md. Abdul Mannan² and Saurav Dey Shuvo ${ }^{1}$ \\ ${ }^{1}$ Department of Meteorology, University of Dhaka, Dhaka 1000, Bangladesh \\ ${ }^{2}$ Bangladesh Meteorological Department, Dhaka, Bangladesh \\ Manuscript received: 25 August 2021; accepted for publication: 28 November 2021
}

\begin{abstract}
An attempt has been made to study the prediction of the track of Super Cyclone (SuC) Amphan that formed on 13 May over Southeast Bay of Bengal (BoB) and made landfall to West Bengal-Bangladesh Coast on 20 May 2020 using Advanced Research WRF (ARW) dynamics of Weather Research and Forecasting (WRF) model. Model integration has been carried out using two-way interactive nesting domains with resolutions of $27 \mathrm{~km}$ for domain 1 and $9 \mathrm{~km}$ for domain 2 respectively covering the Bay of Bengal. Simulations are performed at an interval of 6 hours with ICs using the National Centre for Environmental Prediction (NCEP) global forecast system (GFS) $0.25^{\circ}$ analysis and forecasts. To understand the applicability of the model in predicting the track along with landfall position and landfall time, nine real-time numerical forecasts have been carried out with model simulation starting at 00 UTC of 13 May, 14 May, 15 May, 16 May, 17 May, 18 May, 19 May, 20 May and 21 May 2020. The experiments with initial time on 16 May, 17 May, 18 May, 19 May, and 20 May 2020 have produced the best performance for the track and intensity prediction which are comparable to those provided by Bangladesh Meteorological Department (BMD) and Regional Specialized Meteorological Centre (RSMC). The tracks are produced based on the distribution of sea level pressure and vorticity. The model shows that the track prediction accuracy increases as the lead time decreases with the updated ICs. The results obtained from the model are in good agreement with the reported data. The experiment of SuC Amphan produced better track and intensity predictions with lead-time of 144, 120, 96, 48, and 24 hours. The results demonstrate that the model is capable to produce the track of SuC Amphan with reasonable accuracy.
\end{abstract}

Keywords: Cyclone track, Bay of Bengal, Prediction, WRF-ARW, Landfall time, Landfall position

\section{INTRODUCTION}

The coastal zone of Bangladesh is highly vulnerable to tropical cyclones. The frequency of severe cyclones has been found to rise during the recent decades. Fourteen of the nineteen coastal districts of Bangladesh are found to be high or moderate cyclone-risk prone areas, which are currently the home of around 30.5 million people. The cyclones that hit Bangladesh are mostly formed in the Bay of Bengal $(\mathrm{BoB})$ and their destructive force is primarily due to the accompanying high wind and storm surge. Bangladesh has experienced the deadliest Super Cyclonic Storm Amphan in May 2020. An accurate track forecast and intensity prediction is essential to reduce the devastation. It is therefore of great importance to understand the mechanism of cyclone development, which is a prerequisite for accurate prediction of the formation, intensification, and landfall. The prediction and early warning of the

Corresponding author: Sabikun Nahar

Email: sabikunmoly93@gmail.com

DOI: https://doi.org/10.3329/dujees.v10i2.57513 tropical cyclones with sufficient lead-time help in preparedness for taking safety measures, undertake rescue operations, and post-cyclone recovery and rehabilitation measures.

Tropical cyclones move under the influence of the wind fields, however, there are more complex factors that control the movement of the tropical cyclones (Harr and Elsberry, 1995). Over the period, some advances have been made in cyclone track prediction (McAdie and Lawrence, 2000) using numerical models' outputs. However, the forecasters still need to attain their desired accuracy levels. The gap is primarily due to errors creeping when the satellite observations of the atmosphere (Velden et al., 1997), are dovetailed into numerical models (Velden et al., 1998), and the inherent model biases (Krishnamurti et al., 2000). Considerable accuracy in cyclone intensity prediction is seen when the initial data is updated progressively, at least in 12-hour intervals, the deviations are found larger as one tends to move towards larger time intervals, beyond 48 hours of cyclogenesis and this leads to a situation of estimating the final intensity on a lower scale than the actual, due to statistical smoothening. 
The Super Cyclone (SuC) Amphan originated from the remnant of a Low-Pressure System near the Equatorial Easterly wave over the south Andaman Sea and adjoining southeast Bay of Bengal (BoB) on 13 May 2020. It concentrated into a depression (D) over southeast $\mathrm{BoB}$ in the early morning and further intensified into a deep depression (DD) in the same afternoon. Moving north-northwestwards it intensified into Cyclonic Storm over southeast $\mathrm{BoB}$ in the evening of 16 May. Again, moving nearly northwards it intensified into a Severe Cyclonic Storm (SCS) over southeast $\mathrm{BoB}$ in the morning of 17 May, further intensified into a Very Severe Cyclonic Storm (VSCS) by 12 UTC of 17 May, then again into an Extremely Severe Cyclonic Storm (ESCS) in the early morning of 18 May and finally into a Super Cyclonic Storm (SuCS, Wind speed $>221 \mathrm{~km} / \mathrm{hr}$ ) at around 06 UTC of

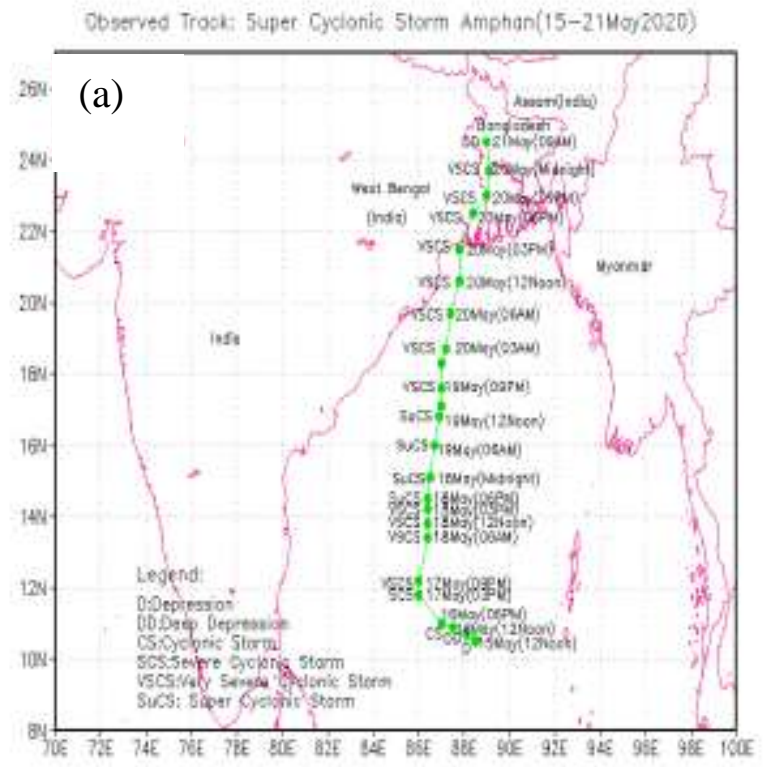

18 May. It maintained its intensity before weakening into an ESCS over West-central BoB by 06 UTC of 19 May and crossed West Bengal - Bangladesh coasts near Sundarbans as a VSCS between 10:00 and 11:00 UTC of 20 May with a maximum sustained wind speed of $155-165 \mathrm{~km} / \mathrm{hr}$. Through continuously moving north-northeastwards during 20 May, it weakened into an SCS over Bangladesh \& adjoining West Bengal around 1800 UTC of 20 May 2020. Then it began to weaken into a CS over Bangladesh in the early morning of 21 May. (https://rsmcnewdelhi.imd.gov.in/archivereport.php). Observed track of SuC Amphan over the Bay of Bengal of Bangladesh Meteorological Department (BMD) and India Meteorological Department (IMD) are given in Figure 1.

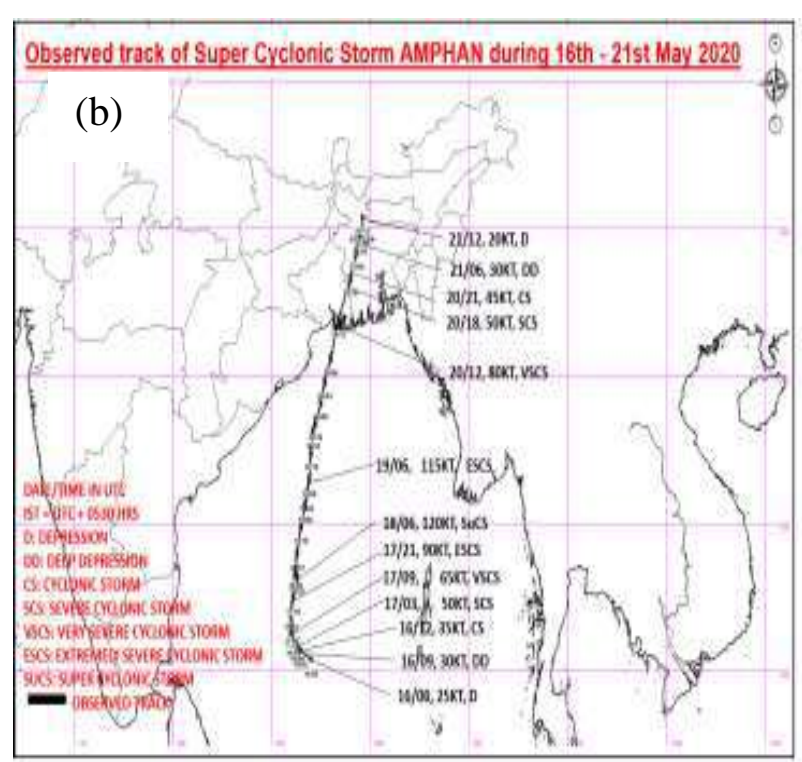

Figure 1: Observed Track of SuC Amphan for (a) BMD and (b) RSMC.

The primary objective of this study is to simulate the track of the SuC Amphan along with landfall position and landfall time using the WRF-ARW model and the secondary objective is to compare the model generated cyclone track with the observation.

\section{MODEL EXPERIMENTAL SETUP AND DATA USED AND METHODOLOGY}

The Advanced Research WRF (ARW) dynamic core of the Weather Research and Forecasting (WRF) Model (hereinafter referred to as WRF-ARW) is actually a subset of the WRF modeling system that encompasses all the physics schemes along with the numeric/dynamics options, the initialization routines, and also a data assimilation package (Skamarock et al., 2008). For this research, WRF-ARW (version 4.1), which released in April 2019 is used.

\section{Model Experimental Setup}

The WRF-ARW model is run in two-way interactive double nested domains at 27 and $9 \mathrm{~km}$ horizontal resolutions over the Bay of Bengal. The model is configured using Mercator map projection and 35 vertical levels. The domain configuration is shown in Figure 2. The Milbrandt-Yau Double Moment 7 Class Scheme is used for microphysics. 
This scheme includes separate categories for hail and graupel with double-moment clouds, rain, ice, snow, graupel, and hail. Kain Fritsch Scheme is used for cumulus parameterization (Kain, 2004). It is deep and shallow convection sub-grid scheme using a mass flux approach with downdrafts and CAPE removal time scale closure. Cumulus Convection (CC) and PBL processes can play important role in the development and intensification of TCs in numerical models. Yonsei University Scheme (YSU) is used for the planetary boundary layer which is a non-local-K scheme with explicit entrainment layer and parabolic $\mathrm{K}$ profile in the unstable mixed layer (Hong et al., 2006). Short wave and longwave radiations have been treated with Dudhia Schemes, a simple downward integration allowing efficiently for clouds and clearsky absorption and scattering (Dudhia, 1989) and Rapid Radiative Transfer Model (RRTM), an accurate scheme using look-up tables for efficiency (Mlawer et al., 1997) respectively.

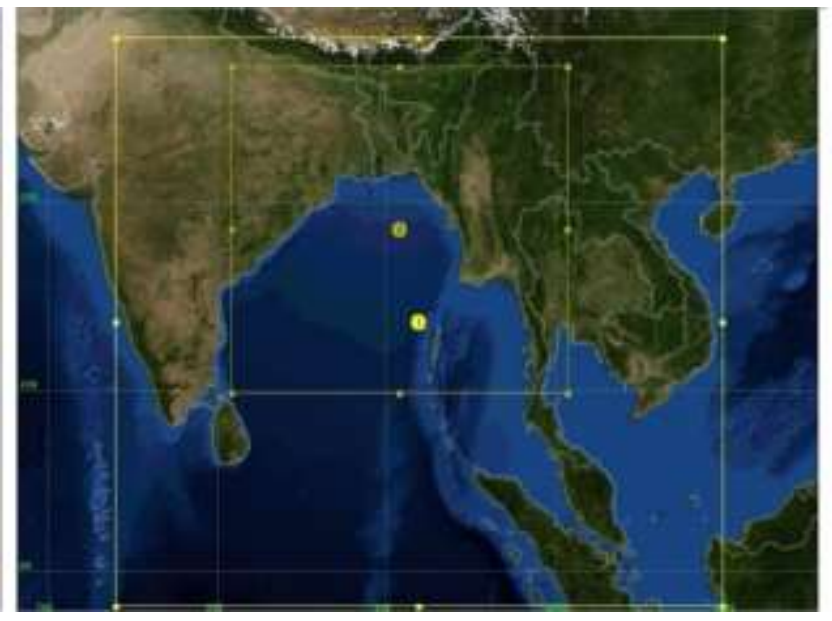

Figure 2: WRF Model Domain Setup

\section{Data used}

The observed track data of the BMD and RSMC are used to compare with or validate the model simulated track based on the horizontal distribution of relative vorticity and sea level pressure fields. The United States Geological Survey (USGS) terrain data at 30 -sec intervals are used to simulate the topographical features and land use/vegetation fields. The model is initialized with NCEP GFS Analysis and Forecast Grids data at 0.25-degree horizontal resolution (https://rda.ucar.edu/datasets/ds084.1) and 6-hours temporal resolution is used as the initial and lateral boundary conditions of the model. The data used for subsequent verification of model output:
RSMC, New Delhi Best Track data and BMD track data are used for the verification of the model output.

\section{Methodology}

WRF model is run for $9,8,7,6,5,4,3,2$, and 1 day ahead of its landfall based on the IC at 00 UTC of 13, 14, 15, 16, 17, 18, 19, 20 and 21 May 2020 respectively. After that model results are presented in the graphical and tabular forms and compared with the BMD and RSMC tracks data. For cyclone formation and intensity prediction, various meteorological parameters are analyzed.

Grid Analysis and Display System (GrADS) software is used for the plotting of sea level pressure from the date of 13 May 00 UTC to 22 May 00 UTC at 6- hours intervals which are based on 9- days model run. Plotting of geopotential height at different vertical levels are also done using GrADS. Each parameter is plotted based on the different ICs from 00 UTC of 13 May to 00 UTC of 22 May. Relative vorticity is plotted at surface level, $850 \mathrm{hPa}$, and 925 $\mathrm{hPa}$ levels and Divergence at $500 \mathrm{hPa}$, Streamflow at sea level is analyzed for knowing cyclone formation and intensification. The model simulated track is prepared based on the positions of the centers of the cyclone as defined by sea level pressure and relative vorticity derived at a 6-hours interval from the model run with a different initial condition such as 13 May, 14 May, 15 May, 16 May, 17 May, 18 May, 19 May, 20 May and finally 21 May. Track error of sea level pressure and vorticity at different ICs are estimated by calculating the distance based on central latitude and longitude of observed and simulated data. After that average error is calculated for 6 hours intervals based on 13 May to 21 May. Then a diagram is plotted. From track based on SLP and vorticity are compared with the RSMC and BMD observed landfall time.

\section{RESULTS}

\section{Prediction of SuCS Amphan track based on Vorticity}

The cyclone positions are determined by the location of the center point of simulated positive vorticity field. The observed and forecast tracks are presented based on ICs of 13, 14, 15, 16, 17, 18, 19, and 20 May 2020 as given Figures 3 and 4. The forecast positions are shown at 6 hours interval. Forecasts based on 13 and 14 May 2020 ICs do not show clear movement and landfall of the cyclone. Simulation with the ICs of 14, 15 and 16 May 2020 
indicates northwestward movement in the beginning and then northward and finally northeastwards. The tracks on these days suggested the TC would strike West Bengal coast, while it predicted that the TC would cross West Bengal near Sundarban, Bangladesh. Tracks based on the ICs of 17, 18, 19 and 20 May consistently shows the TC would cross the West Bengal coast near Sundarban, Bangladesh. Finally, simulation with the IC of 21 May specify that the cyclone would lay over north Bangladesh.

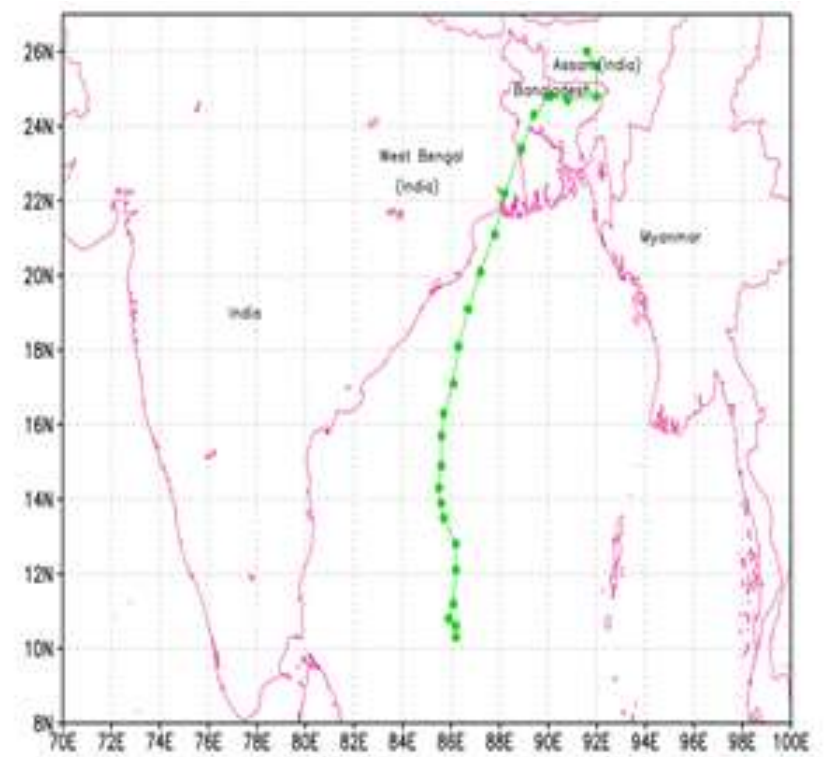

Figure 3: Predicted Track of SuCS 'AMPHAN' during 1521 May 2020 Based on Vorticity

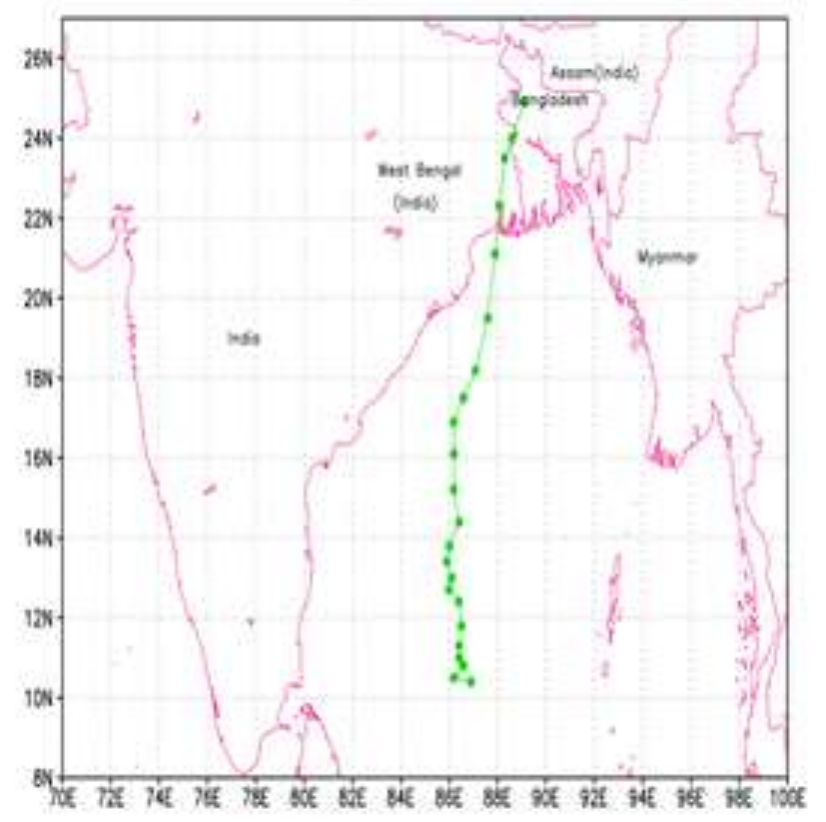

Figure 4: Predicted Track of SuCS 'AMPHAN' during 1621 May 2020 Based on Vorticity

\section{Prediction of SuC Amphan Track Using Estimated Central Pressure}

The simulated cyclone positions were determined by the location of the center point of minimum sea level pressure. The simulated track was fairly accurate with track error of $49.9 \mathrm{~km}$, when compared with the observed positions. Considering the BMD recorded landfall location, the simulated landfall was $11 \mathrm{~km}$ distance than that of the observed cyclone (at 12 UTC 20 May). However, the simulated cyclone landfall occurred at nearly the same location (eye position: $21.78 \mathrm{~N}, 89.58 \mathrm{E})$ on the coast as that of the observed cyclone (eye position: $21.78 \mathrm{~N}, 89.48 \mathrm{E}$ ). However, the $24 \mathrm{hr}$ predicted track deviated $49.9 \mathrm{~km}$ and $48 \mathrm{hrs}$ forecast tracks $51.3 \mathrm{~km}$ and indicated landfall at West Bengal near fairly close to the actual.

The $72 \mathrm{hrs}$ predicted track initially deviated to $54.1 \mathrm{~km}$ and then re-curve and move towards the northeastward following the observed track. The model predicted landfall point match with that of observed in reasonably well. The $96 \mathrm{hrs}$ predicted track initially deviated to $60 \mathrm{~km}$ from the observed track. The model therefore captured more or less realistic track of the cyclone with some position and timing errors. The landfall accuracy increases as the prediction time decreases using updated ICs. The model simulated tracks of Amphan show that the model prediction experiments captured well the direction of motion, re-curvature and probable areas of landfall as compared with that of observed track. So, by updating initial data, the simulated track became close to the observed track.

\section{Track Forecast Position Error}

The track forecast position errors in sea level pressure show that at 00UTC of 20 May 2020 produces comparatively less error than any other ICs. The forecast time position errors are analyzed for evaluating and understanding the model performances. Table 1 shows that 20 May predictions exhibit lower position errors whereas 19 May, 18 May, 17 May, 16 May, 15 May, 14 May and 13 May predictions have comparatively higher position errors. The track position errors of the SuC Amphan for forecasting are found respectively as $49.9 \mathrm{~km}$ for 24 hours, $51.3 \mathrm{~km}$ for 48 hours, $54.1 \mathrm{~km}$ for 72 hours, and $73.6 \mathrm{~km}$ for 120 hours of predictions. The error tends to decrease substantially with decreasing lead time. 


\section{Landfall Forecast Error}

The spread of simulated tracks from the beginning of cyclone formation is more and the landfall positions are more diverse. Simulation reveals that as the forecasting length decreases, the landfall error also decreases. From the mature stage of the cyclone predicted tracks becomes closer to the observed track for sea level pressure and vorticity. The landfall position errors based on sea level pressure, vorticity at surface level is presented in Tables 2. Table 2 also shows that the model can generate northeast, northwest, north, and north-northeastward movement of the cyclone very well. It indicates that 24-, 48- and 72-hours tracks are closer to the RSMC and BMD track compared to 96 hours observed tracks.

Table 1: WRF Model Simulated Track Forecast Position Errors Based on SLP and Surface Level Relative Vorticity.

\begin{tabular}{|c|c|c|}
\hline IC at 00 UTC & $\begin{array}{c}\text { Track Error }(\mathrm{km}) \\
\text { for SLP }\end{array}$ & $\begin{array}{c}\text { Track Error }(\mathrm{km}) \\
\text { for Vorticity }\end{array}$ \\
\hline 13 May & 314.6 & 319.6 \\
\hline 14 May & 161.9 & 176.3 \\
\hline 15 May & 149.0 & 148.1 \\
\hline 16 May & 73.6 & 77.9 \\
\hline 17 May & 60.0 & 71.8 \\
\hline 18 May & 54.1 & 54.2 \\
\hline 19 May & 51.3 & 52.0 \\
\hline 20 May & 49.9 & 50.3 \\
\hline
\end{tabular}

Table 2: Track Forecast Landfall Position Errors Based on SLP and Surface Level Relative Vorticity.

\begin{tabular}{|c|c|c|}
\hline $\begin{array}{c}\text { IC at 00 } \\
\text { UTC }\end{array}$ & $\begin{array}{c}\text { Landfall distance } \\
(\mathrm{km}) \text { for SLP }\end{array}$ & $\begin{array}{c}\text { Landfall distance } \\
(\mathrm{km}) \text { for vorticity }\end{array}$ \\
\hline 13 May & 460.69 & 466.82 \\
\hline 14 May & 113.25 & 442.88 \\
\hline 15 May & 187.97 & 184.39 \\
\hline 16 May & 90.71 & 103.77 \\
\hline 17 May & 56.09 & 88.68 \\
\hline 18 May & 73.79 & 79.32 \\
\hline 19 May & 50.3 & 40.64 \\
\hline 20 May & 11 & 0 \\
\hline
\end{tabular}

The landfall forecast errors are investigated for evaluating the model performances. The SuC Amphan landfall time is close to 12 UTC of 20 May. Landfall forecast error is calculated from the central latitude and longitude position of the cyclone at 12 UTC of every initial condition. Based on 13 to 20 May initial condition wind speed variation distance error with landfall time is given in Table 3, and from all simulation shows highest wind speed found at 17,18 , 19 May in the different ICs. In the mature stage, the system became the more violent and in this time the cyclone formed into a Super Cyclonic Storm as all simulation shows wind speed exceeds $221 \mathrm{~km} / \mathrm{hr}$. Simulated maximum vorticity, maximum wind speed and minimum sea level pressure for different lead time is given in Table 4.

Table 3: Track Forecast Landfall Time Position Error Based on Wind Speed (kmph) Distance Error

\begin{tabular}{|c|c|}
\hline IC at 00 UTC of & Landfall wind speed (kmph) \\
\hline 13 May & 122.7 \\
\hline 14 May & 109.08 \\
\hline 15 May & 99.0 \\
\hline 16 May & 92.6 \\
\hline 17 May & 94.9 \\
\hline 18 May & 145.7 \\
\hline 19 May & 132.1 \\
\hline 20 May & 96.3 \\
\hline
\end{tabular}

Table 4: Landfall Time (12 UTC of 20 May) Evolution of MSLP, Maximum Wind Speed $(\mathrm{km} / \mathrm{hr})$, Maximum Vorticity Value $\left(10^{-5} \mathrm{~s}^{-1}\right)$

\begin{tabular}{|l|l|l|l|l|l|l|l|l|}
\hline Parameter & \multicolumn{7}{|c|}{ Simulation Period in hours } \\
\cline { 2 - 9 } & 24 & 48 & 96 & 120 & 144 & 168 & 192 & 216 \\
\hline $\begin{array}{l}\text { Maximum } \\
\text { vorticity } \\
\text { value (10 } \\
\mathrm{s}^{-1} \text { - }\end{array}$ & 129 & 148.6 & 169.6 & 141.0 & 184.6 & 141.0 & 107.1 & 116.2 \\
\hline $\begin{array}{l}\text { Maximum } \\
\text { wind speed } \\
\text { value } \\
\text { (km/hr) }\end{array}$ & 96.3 & 132.1 & 145.7 & 94.9 & 92.6 & 99.0 & 109.0 & 122.7 \\
\hline $\begin{array}{l}\text { Minimum } \\
\text { sea level } \\
\text { pressure } \\
\text { value (hPa) }\end{array}$ & 564. & 959.4 & 950.2 & 975.9 & 975.7 & 971.2 & 959.8 & 958.5 \\
\hline
\end{tabular}


Relationship among Central Pressure, Maximum Surface Wind Speed and Maximum Surface Vorticity

Simulation reveals that the pressure drop varies inversely with the maximum wind speed and the maximum vorticity of the SuC Amphan, as depicted in Figure 5.

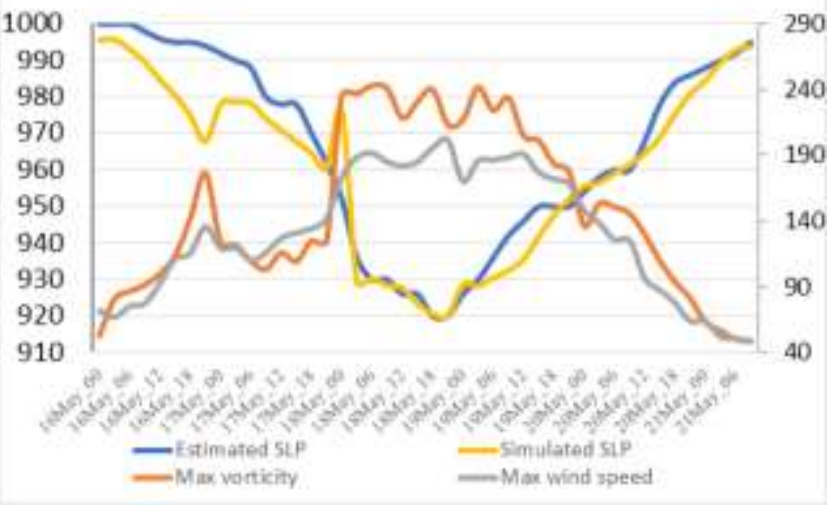

Figure 5: Variation of Minimum SLP, Maximum Wind speed, and Maximum Vorticity Associated with SuC Amphan.

\section{DISCUSSION AND CONCLUSIONS}

The SuC Amphan, which developed over the Bay of Bengal on 13 May 2020 and made landfall on 20 May 2020 is selected in the present study for simulating the track and various meteorological characteristics. WRF model simulation made with 9 different ICs between 00 UTC 13 May to 00 UTC 21 May using six-hourly GFS analysis and forecasts. Important meteorological parameters such as streamflow at sea level, relative vorticity, wind shear, lower-level convergence, upper-level divergence, geopotential height at 850 level, total totals index, etc., are studied for a better understanding of the formation and intensification of the cyclone, where the results also quite closer to the observation. The gradual changes like the storm are captured by the model.

The simulation underestimates the amount of precipitation 00 UTC of 19 May and 00 UTC of 20 May forecast. The track of SuC Amphan by using the WRF-ARW model is very close to the observational track after the intensification of the system but not at the beginning initial time. Regarding track prediction, 24 hours simulation track are the best among other simulation and agreed well with the observed track.
The model simulated ECPs are lower than the observed values at the developing stage and higher than the observed values after the intensification of the system and simulated values are almost close to the observed values at beginning of the system and at the time of recurving of the system. The forecast track errors gradually decreased from initial time in various experiments with the largest errors up to $322 \mathrm{~km}$ with simulations 00 UTC of 13 May at 850 level vorticities.

Finally, it is considered that WRF-ARW Model has better forecast skills to simulate the track of the SuC Amphan. Both the predicted track based on sea level pressure and vorticity can forecast cyclone landfall location and accurate time as the track based on vorticity at different levels gives the better result as well as track based on sea level pressure. Above all experiments with different ICs based on vorticity track can also give better track and intensity prediction as well as minimum sea level pressure.

\section{REFERENCES}

Dudhia, J. (1989). Numerical study of convection observed during the winter monsoon experiment using a mesoscale two-dimensional model. Journal of Atmospheric Sciences, 46(20): 3077-3107.

Harr, P.A. and Elsberry, R.L. (1995). Large-scale circulation variability over the tropical western North Pacific. Part I: Spatial patterns and tropical cyclone characteristics. Monthly Weather Review, 123(5) :1225-1246.

Hong, F., Breitling, R., McEntee, C.W., Wittner, B.S., Nemhauser, J.L. and Chory, J., 2006. RankProd: a bioconductor package for detecting differentially expressed genes in meta-analysis. Bioinformatics, 22 (22): 2825-2827.

Kain, J.S. (2004). The Kain-Fritsch convective parameterization: an update. Journal of Applied Meteorology, 43(1): 170-181.

McAdie, C.J. and Lawrence, M.B. (2000). Improvements in tropical cyclone track forecasting in the Atlantic basin, 1970-98. Bulletin of the American Meteorological Society, 81(5): 989-998.

Mlawer, E.J., Taubman, S.J., Brown, P.D., Iacono, M.J. and Clough, S.A. (1997). Radiative transfer for inhomogeneous atmospheres: RRTM, a validated correlated-k model for the longwave. Journal of Geophysical Research: Atmospheres, 102(D14): 16663-16682. 
Skamarock, W.C., Klemp, J.B., Dudhia, J., Gill, D.O., Barker, D.M., Wang, W. and Powers, J.G. (2008). A description of the Advanced Research WRF version 3. NCAR Technical note-475+ STR.

Velden, C.S., Hayden, C.M., Nieman, S.J.W., Paul Menzel, W., Wanzong, S. and Goerss, J.S., 1997. Uppertropospheric winds derived from geostationary satellite water vapor observations. Bulletin of the American Meteorological Society, 78(2): 173-196.

Velden, C.S., Olander, T.L. and Wanzong, S., 1998. The impact of multispectral GOES-8 wind information on Atlantic tropical cyclone track forecasts in 1995. Part I: Dataset methodology, description, and case analysis. Monthly Weather Review, 126(5): 1202-1218. 
